\title{
BMJ Open Prevalence and genotype distribution of cervical human papilomavirus infection in the pre-vaccination era: a population- based study in the Canary Islands
}

\author{
Miguel Andujar (1D , ${ }^{1}$ Esther Roura, ${ }^{2,3}$ Alejandra Torres, ${ }^{4}$ Begoña Vega, ${ }^{4}$ \\ Marta Pavcovich, ${ }^{1}$ Miguel Angel Sanchez, ${ }^{1}$ Amina Lubrano, ${ }^{4}$ Jose Luis Trujillo, ${ }^{5}$ \\ Lucia Almeida, ${ }^{6}$ Milagros Santana, ${ }^{1}$ Rosaura Hurtado, ${ }^{4}$ Octavio Arencibia, ${ }^{4}$ \\ Virginia Benito, ${ }^{4}$ Norberto Medina, ${ }^{4}$ Sonia Carballo, ${ }^{4}$ Maria del Carmen Camacho, ${ }^{1}$ \\ Arancha Ruiz del Pozo, ${ }^{1}$ Alfoso Quesada, ${ }^{6}$ Eduardo Salido, ${ }^{7}$ Silvia de Sanjosé, ${ }^{8,9}$ \\ Laia Bruni, ${ }^{2,10}$ and the HPV Canary Study Group
}

To cite: Andujar M, Roura E, Torres A, et al. Prevalence and genotype distribution of cervical human papilomavirus infection in the pre-vaccination era: a population-based study in the Canary Islands. BMJ Open 2020;10:e037402. doi:10.1136/ bmjopen-2020-037402

- Prepublication history and additional material for this paper are available online. To view these files, please visit the journal online (http://dx.doi org/10.1136/bmjopen-2020037402).

Received 31 January 2020 Revised 08 April 2020 Accepted 09 July 2020

\section{Check for updates}

(c) Author(s) (or their employer(s)) 2020. Re-use permitted under CC BY-NC. No commercial re-use. See rights and permissions. Published by BMJ.

For numbered affiliations see end of article.

\section{Correspondence to}

Dr Miguel Andujar;

mandsan@gobiernodecanarias. org

\section{ABSTRACT}

Objective National Spanish studies show that prevalence of cervical human papillomavirus (HPV) infection in the female population is increasingly frequent, with an overall estimate of $14 \%$ in women aged 18-65 years. The objective of this study is to know the prevalence and distribution of HPV types in the female population of the Canary Islands prior to the introduction of HPV vaccines and to investigate the associated clinical and sociodemographic factors

Methods Based on the Primary Health Care database, a sample of adult women (aged 18-65 years) of Gran Canaria (GC) and Tenerife (TF) stratified into nine age groups was carried out between 2002 and 2007. Women were contacted by postal letter and telephone call and were visited in their primary care centre. A clinical-epidemiological survey was completed and cervical samples were taken for cytological study and HPV detection. HPV prevalence and its $95 \% \mathrm{Cl}$ were estimated, and multivariate analyses were performed using logistic regression to identify factors associated with the infection.

Results 6010 women participated in the study, 3847 from GC and 2163 from TF. The overall prevalence of HPV infection was $13.6 \%$ (Cl 12.8\%-14.5\%) and $11.1 \%$ (Cl 10.3\%-11.9\%) for high-risk types. The most frequent HPV type was 16 followed by types 51, 53, 31,42 and 59. HPV types included in the nonavalent vaccine were detected in $54.1 \%$ of infected women. Factors associated with an increased risk of infection were: young ages (18-29 years), the number of sexual partners throughout life, not being married, being a smoker, and having had previous cervical lesions or genital warts.

Conclusions It is confirmed that prevalence of HPV infection in the female population of the Canary Islands is high, but similar to that of Spain, HPV 16 being the most frequent genotype. The determinants of infection are consistent with those of other populations.
Strengths and limitations of this study

This is the first prevalence study of human papillomavirus infection in Canary Islands.

- The study design is population-based, including the main healthcare centres of the participant regions.

- Cytological and molecular samples were analysed in the same laboratory by the same staff, using highly sensitive and partially automated techniques that ensured consistency, homogeneity and reproducibility of diagnostic methods.

- Study recruitment time was extensive, from 3 to 6 years depending on the region.

- Characteristics of the study participants could be different over time.

\section{INTRODUCTION}

Cervical cancer is the fourth most common female cancer worldwide and the second most frequent among young women aged 15-44 years, with an estimated 569847 new cases in 2018. ${ }^{1}$ In Spain, cervical cancer is the 15 th most frequent cancer in women (4th in women aged 15-44 years), with an estimated 1942 new cases in 2018. ${ }^{1}$ In the Canary Islands autonomous community, 356 new cases were diagnosed in 2008-2011, with a crude rate of 10.1 cases per 100000 women, ${ }^{2}$ one of the highest incidence rates in Spain. ${ }^{3}$

Human papillomavirus (HPV) is a necessary but not sufficient cause of cervical cancer. ${ }^{4}$ More than 200 HPV genotypes are currently known, epidemiologically classified into low-oncogenic risk (LR-HPV) and highoncogenic risk (HR-HPV) types. ${ }^{5}$ HR-HPV types include 16 and 18 genotypes, present in $>70 \%$ of cervical cancer cases ${ }^{6}$ and included 
in the three prophylactic HPV vaccines currently commercialised. ${ }^{78}$

No robust estimations of HPV infection prevalence are available for the Canary Islands, which hinders comparisons with the rest of Spain. Changes in Spanish women's sexual behaviour in the last decades have leads to increased HPV infection rates (up to $14 \%$ in women aged $18-65$ years, $29 \%$ of them in women younger than 25 years).${ }^{9}$ Baseline prevalence estimations of HPV infection and the genotype distributions are essential to monitor the impact of HPV-vaccination campaigns. Therefore, the goal of this study was to estimate the prevalence and distribution of HPV types in the female population of the Canary Islands before introducing HPV vaccination, as well as to study the clinical and sociodemographic factors associated with HPV infection.

\section{METHODS}

\section{Participants}

The study was conducted between 2002 and 2007 on a sample of women aged 18-65 years living in any of the two most populated Canarian Islands: Gran Canaria and Tenerife. Participants were randomly selected from the regional Health Administration databases, stratified and selected with a probability proportional to the different healthcare areas on both islands. Selected women were stratified into nine age groups (18-24, 25-29, 30-34, $35-39,40-44,45-49,50-54,55-59$ and 60-65 years). The initial sample included 2276 women. For each age group, four reserve groups were obtained to supply the absences or refusals to participate. Participants were contacted by letter and a subsequent telephone call. A visit to the nearest healthcare centre was scheduled. A total of 24345 letters were sent, 15577 in Gran Canaria and 8768 in Tenerife, of which $23.3 \%$ agreed to participate. Women who did not attend the visit were recalled by phone to schedule another visit. Subsequently, a group of 934 women from Gran Canaria asked to participate in the study (volunteers) of which 665 finally attended the arranged appointment.

\section{Patient and public involvement}

No patients or the public were involved in the design, conduct, reporting or dissemination of this study.

\section{Procedures}

Participants were asked to fulfil an informed consent form and to complete a clinical and epidemiological questionnaire (adapted from International Agency for Research on Cancer (IARC) surveys). For cytological collection, the wooden Ayre spatula and endocervical brush (cytobrush) were used, stained with the Papanicolaou technique and the cytological diagnosis was made by a single pathologist according to the criteria of the Bethesda system. For the molecular study, a sterile cotton-tipped polystyrene swab without culture medium (Deltalab, Spain) was used. The obtained cell pellet was subjected to enzymatic digestion with stirring for 2 hours at $55^{\circ} \mathrm{C}$ with proteinase $\mathrm{K}$ following the inactivation of the process with incubation for $10 \mathrm{~min}$ at $90^{\circ} \mathrm{C}$ and subsequent centrifugation, obtaining DNA from the sample supernatant.

To detect HPV infection, two separated PCR were conducted: one using My09/My11 consensus primer and the other using Gp5+/Gp6+ consensus primer. DNA quality was evaluated by PCR testing for the $\beta$-globin gene. Samples that were negative for both HPV DNA and $\beta$-globin were excluded from the final analysis. Samples showing positive results for any of the HPV PCR reactions or any cytological alteration (atypical squamous cells of undetermined significance (ASCUS) or higher) were genotyped using the Linear Array HPV Genotyping Test (CE-IVD; Roche Diagnostics) or the INNO-LIPA HPV Genotyping Extra Amp kit (Immnogenetics (now Fujirebio Europe), Belgium).

\section{Statistical analyses}

Descriptive analysis of sociodemographic variables was conducted, globally and stratified according to the study subpopulation (ie, selected participants from Gran Canaria, volunteers from Gran Canaria, selected participants from Tenerife). Estimated HPV infection prevalence and genotype distribution and corresponding 95\% CIs (Confidence Interval) were calculated as the number of HPV-positive women among the total number of women tested for each age group, study subpopulation and cytological outcome (normal, abnormal). For each genotype, estimated prevalences were calculated independently including the presence of a given type either as a single type or in combination with others (multiple infections). Multivariate analysis was conducted using basic and adjusted logistic regression models in order to assess potential risk factors associated with infections by any HPV type and by HR types. Variables were introduced one by one into a basic regression model adjusted for age group and subpopulation. Variables showing statistically significant association ( $p$ value $<0.05$ ) were kept as adjustment variables in the final model. Statistical analysis was carried out with the $\mathrm{R}$ software ( $\mathrm{R}$ Development Core Team, 2005, http://www.r-project.org).

\section{RESULTS}

\section{Study population}

Table 1 shows the characteristics of the study population. A total of 6091 women were included: 3212 selected from the general Gran Canaria population $(52.7 \%), 665$ volunteers from Gran Canaria $(10.9 \%)$ and 2214 selected from Tenerife $(36.3 \%)$. Up to $8.4 \%$ of participants were not born in Spain and came mostly from Latin American countries $(5.4 \%)$; participants' mean age was 40.7 years; $64.4 \%$ were married at recruitment; $77.5 \%$ had been pregnant at least once and the mean number of children was 2.2. Regarding cytology screening, $53.7 \%$ of subjects had undergone more than five cytological studies in their lives, while $3.5 \%$ of them had never undergone 
Table 1 Characteristics of the study participants $(n=6091$ women)

\begin{tabular}{|c|c|}
\hline Study sample characteristics & N (\%) \\
\hline \multicolumn{2}{|l|}{ Distribution by population } \\
\hline Gran Canaria (general population) & $3212(52.7)$ \\
\hline Gran Canaria (volunteers) & $665(10.9)$ \\
\hline Tenerife & $2214(36.3)$ \\
\hline \multicolumn{2}{|l|}{ Country of birth } \\
\hline Spain & $5397(91.6)$ \\
\hline Europe (excluding Spain) & $111(1.9)$ \\
\hline Northern Africa & $20(0.3)$ \\
\hline Sub-Saharian Africa & $15(0.3)$ \\
\hline Latin America and Caribbean & $318(5.4)$ \\
\hline Asia and Oceania & $30(0.5)$ \\
\hline Missing data & $200(-)$ \\
\hline \multicolumn{2}{|l|}{ Age distribution (years) } \\
\hline $18-24$ & $572(9.4)$ \\
\hline $25-29$ & $663(10.9)$ \\
\hline $30-34$ & 905 (14.9) \\
\hline $35-39$ & $902(14.8)$ \\
\hline $40-44$ & $793(13.0)$ \\
\hline $45-49$ & $631(10.4)$ \\
\hline $50-54$ & $613(10.1)$ \\
\hline $55-59$ & $502(8.2)$ \\
\hline $60-65$ & $510(8.4)$ \\
\hline \multicolumn{2}{|l|}{ Marital status } \\
\hline Single & $1396(22.9)$ \\
\hline Married/De facto partnership & $3919(64.4)$ \\
\hline Divorced/Separated & $573(9.4)$ \\
\hline Widowed & $195(3.2)$ \\
\hline Missing data & $8(-)$ \\
\hline \multicolumn{2}{|l|}{ Pregnancies } \\
\hline No & $1343(22.5)$ \\
\hline Yes & $4613(77.5)$ \\
\hline Missing data & $135(-)$ \\
\hline \multicolumn{2}{|l|}{ Number of live births* } \\
\hline 0 & $28(0.7)$ \\
\hline 1 & $1237(28.7)$ \\
\hline 2 & $1786(41.5)$ \\
\hline 3 & 789 (18.3) \\
\hline 4 & $277(6.4)$ \\
\hline$\geq 5$ & $186(4.3)$ \\
\hline Missing data & $310(-)$ \\
\hline \multicolumn{2}{|l|}{ Sexually transmitted disease } \\
\hline Never & $5882(96.6)$ \\
\hline Evert & $209(3.4)$ \\
\hline Syphilis $\ddagger$ & $30(0.5)$ \\
\hline
\end{tabular}

Continued
Table 1 Continued

\begin{tabular}{lr}
\hline Study sample characteristics & N (\%) \\
\hline Genital herpes $\ddagger$ & $51(0.8)$ \\
Gonorrhoea $\neq$ & $23(0.4)$ \\
HIV $\neq$ & $7(0.1)$ \\
Genital warts $\ddagger$ & $120(2.0)$ \\
Chlamydiał & $30(0.5)$ \\
Genital ulcer & $16(0.3)$ \\
Others $\ddagger$ & $72(1.2)$ \\
Smoking status & \\
Never smoked & $3443(56.5)$ \\
Ex-smoker & $913(15.0)$ \\
Current smoker & $1735(28.5)$
\end{tabular}

Previous cervical pap smears

$\begin{array}{lr}\text { None } & 216(3.5) \\ 1 & 493(8.1) \\ 2-3 & 1056(17.3) \\ 4-5 & 772(12.7) \\ >5 & 3273(53.7) \\ \text { Do not know } & 281(4.6)\end{array}$

Do not know 281 (4.6)

Previous cervical lesions§

No $\quad 4837$ (92.5)

Yes $385(7.4)$

Do not know $\quad 5(0.1)$

Missing data $648(-)$

Age at first sexual intercourse (years)

$<15 \quad 187(3.1)$

$15-16 \quad 828(13.6)$

$17-18 \quad 1863(30.6)$

$19-20 \quad 1281(21.0)$

21-25 $1421(23.3)$

$>25 \quad 442(7.3)$

Missing data $69(-)$

Lifetime number of sexual partners

$\begin{array}{lc}1 & 3232(53.9) \\ 2-3 & 1571(26.2) \\ 4-5 & 614(10.2) \\ 6-10 & 405(6.8) \\ 11-20 & 126(2.1) \\ >20 & 49(0.8) \\ \text { Missing data } & 94(-)\end{array}$

Contraceptive methods usedף

Oral contraceptives $\quad 4664$ (76.6)

IUD 1133 (18.6)

Condom 4522 (74.2)

Rhythm method/Coitus interruptus 3049 (50.1)

Diaphragm/Spermicide 234 (3.8) 


\begin{tabular}{ll} 
Table 1 Continued & \\
\hline Study sample characteristics & N (\%) \\
\hline Injection/Implant & $253(4.2)$ \\
Tube ligation & $802(13.2)$ \\
Vasectomy & $549(9.0)$ \\
\hline
\end{tabular}

*Among ever pregnant women $(n=4613)$.

†Includes syphilis, genital herpes, gonorrhoea, HIV (positive test), genital warts, chlamydia, genital ulcer, others.

fDo not add the total of women because a woman could have more than one sexually transmitted disease in lifetime.

$\S$ Among women with a previous pap smear $(n=5875)$.

qDo not add the total of women because a woman can use more than one contraceptive in lifetime.

one. Regarding HPV infection-related epidemiological factors, $56.5 \%$ of subjects were non-smokers and $28.5 \%$ were smokers at recruitment; $53.9 \%$ of subjects had only one sexual partner and $47.3 \%$ were younger than 19 years at first sexual intercourse. Demographic characteristics were slightly different between both islands: education level, proportion of smokers and number of sexual partners were statistically higher in Tenerife than in Gran Canaria. Regarding the subgroup of Gran Canaria volunteers, they were younger, with a high level of education, more divorced or separated, ex-smokers and with more previous cervical pap smears compared with the general population of the island (see online supplementary table $1)$.

\section{Prevalence of cervical HPV infection}

For the prevalence study, 6010 women were included in the analysis after excluding 81 women due to poor DNA quality in their samples. Prevalence of any-type HPV infection was $13.6 \%$ (95\% CI 12.8 to 14.5 ) while the prevalence of HR-HPV infection was $11.1 \%$ (95\% CI 10.3 to 11.9 ) (table 2). The youngest age group (18-24 years) showed the highest prevalence with $26.7 \%$ of any-type HPV

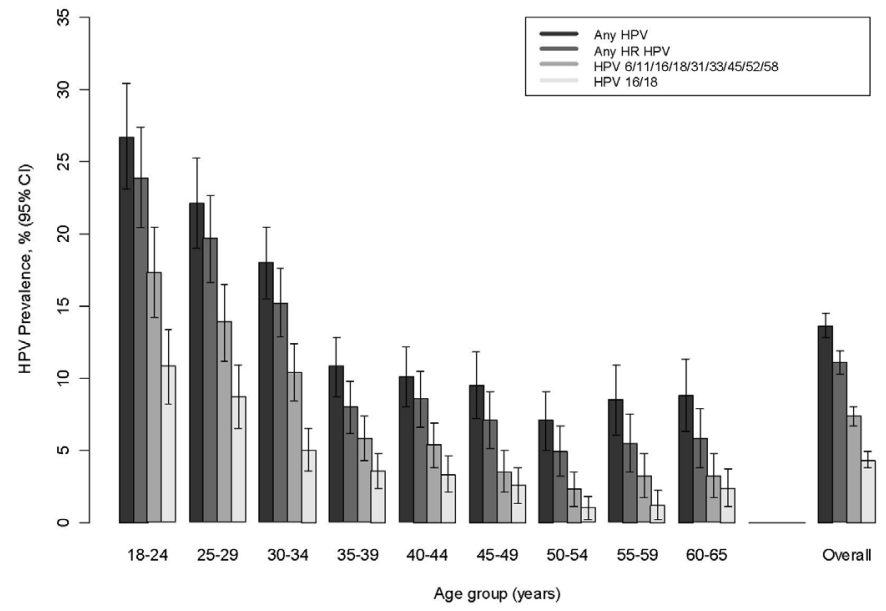

Figure 1 Overall prevalence and age-specific prevalence of cervical human papillomavirus (HPV) infections by any HPV type, any high-risk (HR)-HPV type, HPV types 16/18 and HPV types 6/11/16/18/31/33/45/52/58.

infection (95\% CI 23.1 to 30.4). Prevalence progressively decreased with increasing age, although the two oldest groups (55-65 years) showed a slightly non-significant increase compared with the immediately younger group (figure 1).

Although volunteers from Gran Canaria showed higher prevalence of any-type HPV infection than participants from the general population from both Gran Canaria (14.5\%, 95\% CI 11.8 to 17.2 vs $12.7 \%, 95 \%$ CI 11.6 to 13.9; see online supplementary table 2), the difference was not statistically significant. A comparison between the two populations from Gran Canaria (general population and volunteers) and the population from Tenerife showed statistically significant differences in HR-HPV infection prevalence $(10.6 \%, 95 \%$ CI 9.6 to 11.6 vs $12.1 \%$, $95 \%$ CI 10.7 to $13.4, \mathrm{p}=0.002$; see online supplementary table 2).

Table 2 Prevalence of human papillomavirus (HPV) by age group for any type and for any high-risk (HR) type ( $n=6010$ women)

\begin{tabular}{|c|c|c|c|c|}
\hline Age group (years) & $\begin{array}{l}\text { Number of tested } \\
\text { women }\end{array}$ & $\begin{array}{l}\text { Number of HPV-positive } \\
\text { women }\end{array}$ & $\begin{array}{l}\text { Any HPV prevalence }(\%, \\
95 \% \mathrm{Cl})\end{array}$ & $\begin{array}{l}\text { Any HR-HPV prevalence* } \\
(\%, 95 \% \mathrm{Cl})\end{array}$ \\
\hline $18-24$ & 565 & 151 & 26.7 (23.1 to 30.4 ) & 23.9 (20.4 to 27.4 ) \\
\hline $25-29$ & 655 & 145 & 22.1 (19.0 to 25.3 ) & 19.7 (16.6 to 22.7 ) \\
\hline $30-34$ & 894 & 161 & 18.0 (15.5 to 20.5) & 15.2 (12.9 to 17.6$)$ \\
\hline $35-39$ & 890 & 96 & $10.8(8.7$ to 12.8$)$ & 8.0 (6.2 to 9.8$)$ \\
\hline $40-44$ & 783 & 79 & 10.1 (8.0 to 12.2$)$ & 8.6 (6.6 to 10.5$)$ \\
\hline $45-49$ & 622 & 59 & 9.5 (7.2 to 11.8$)$ & 7.1 (5.1 to 9.1 ) \\
\hline $50-54$ & 607 & 43 & 7.1 (5.0 to 9.1 ) & 4.9 (3.2 to 6.7$)$ \\
\hline $55-59$ & 495 & 42 & 8.5 (6.0 to 10.9$)$ & 5.5 (3.5 to 7.5 ) \\
\hline $60-65$ & 499 & 44 & 8.8 (6.3 to 11.3$)$ & 5.8 (3.8 to 7.9$)$ \\
\hline Total & 6010 & 820 & 13.6 (12.8 to 14.5$)$ & 11.1 (10.3 to 11.9 ) \\
\hline
\end{tabular}

${ }^{*} \mathrm{HR}$-HPV types include high-risk types and possibly/probably high-risk types: 16, 18, 31, 33, 35, 39, 45, 51, 52, 56, 58, 59, 53, 66, 67, 68, 69, 69/71, 70, 73. 
Table 3 shows the distribution of the most frequent HPV genotypes. Single-type HPV infection was detected in $6 \%$ of subjects and multiple infections in $7.2 \%$ (corresponding to $43.8 \%$ and $52.8 \%$ of all HPV-positive women, respectively). Among HR-HPV types, type 16 was the most frequent one found in $27.8 \%$ of positive women (including both single and multiple HPV types), followed by types $51(13.7 \%), 53(13.3 \%), 59$ (9.9\%), 31 (8.5\%), $52(7.7 \%)$ and $18(6.1 \%)$.

Among LR-HPV types, type 42 was the most common one $(9.3 \%)$. In an analysis combining the genotypes included in the HPV vaccines, $31.8 \%$ of HPV-positive women were infected by types 16 and/or 18 while the percentage increased to $36.2 \%$ when types 6 and/or 11 were added and to $54.1 \%$ when the nine types included in the nonavalent vaccine were considered. Figure 1 and online supplementary table 3 show the genotype distribution per age group.

\section{Cytopathological study and cervical HPV infection}

The cytological study yielded 317 pathological findings $(5.3 \%$ ) with $69.1 \%$ (95\% CI 64.0 to 74.2 ) of HPV positivity vs 5693 non-pathological cytologies (94.7\%) with $10.6 \%$ (95\% CI 9.8 to 11.4) of HPV positivity (see online supplementary table 4), 214 cases of ASCUS were detected $(3.6 \%)$ with $60.7 \%$ of HPV positivity, 91 cases of low-grade squamous intraepithelial lesions (LSIL) $(1.5 \%)$ with $86.8 \%$ of HPV positivity and 12 cases of highgrade squamous intraepithelial lesions or worse (HSIL+) $(0.2 \%)$ with $83.3 \%$ of HPV positivity. Genotype 16 was the most frequently type found in these cytological alterations. Multiple infections were more frequent in women with LSIL or HSIL+ as compared with ASCUS (see online supplementary table 5).

\section{Cervical HPV infection and associated risk factors}

Considering all cases of cervical HPV infection (LRHPV and HR-HPV) and according to the final adjusted model, the following statistically significant variables were detected in the association with HPV infection: younger ages (18-29 years, with a significant lineal trend), not married, smokers, more than one sexual partner (statistically significant trend), history of cervical alterations or genital warts and practising coitus interruptus (table 4). When only cases of HR-HPV cervical infection were considered, the same variables showed statistical significance except for practising coitus interruptus (see online supplementary table 6).

\section{DISCUSSION}

\section{Prevalence of cervical HPV infection}

The prevalence of cervical HPV infection (LR-HPV and HR-HPV) in the whole studied population was $13.6 \%$ and $11.1 \%$ for HR-HPV. HPV prevalence in Spain reported in other published studies ranges from $2.7 \%$ to $17.5 \% .^{9-15}$ Two published studies were population-based: one by de Sanjosé $e t a l^{10}$ with a random sample of 973 women from the metropolitan area of Barcelona reporting an HPV prevalence of $3.4 \%$ (95\% CI 2.3 to 4.5 ), which is rather lower than ours, and one by García $e t$ al ${ }^{15}$ conducted in Castilla y León and reporting 9.6\% of HPV prevalence, closer to ours. Differences between both studies could be explained by changes in sexual behaviour in the Spanish population in recent years, with lower age at first sexual intercourse and more sexual partners. ${ }^{16}$

Non population-based studies include CLEOPATRE (Prevalence and Genotype Distribution of Human Papillomavirus Infection of the Cervix in Spain), ${ }^{9}$ a study conducted in 17 Autonomous Communities in Spain, using the HC2 test and reporting 14.3\% (95\% CI 13.1 to 15.5) of HPV prevalence and 12.2\% (95\% CI 11.1 to 13.4) of HR-HPV infection, both results were similar to ours.

Studies conducted in other European countries reported varied results, with diverse populations and different HPV testing methods. In a review of 18 European studies conducted in 14 countries using the HPV-test as first screening (HC2 or PCR) the HR-HPV prevalence, standardised by age, ranged from $1.7 \%$ in Spain to $12.5 \%$ in Belgium. ${ }^{17}$ Bruni et al in a meta-analysis including 1 million women worldwide with normal cytological findings observed $8.8 \%$ global adjusted HPV prevalence in Southern Europe, 9\% in Western Europe and 10\% in Northern Europe. ${ }^{18}$ Studies conducted among women from different European screening programmes showed HPV prevalences ranging from $6.4 \%$ in Germany, ${ }^{19} 8.8 \%$ in Italy, ${ }^{20} 13.7 \%$ in France, ${ }^{21} 15.2 \%$ in Belgium, ${ }^{22} 19.4 \%$ in Portugal $^{23}$ to $26.4 \%$ in a population-based study in Denmark. $^{24}$

\section{Prevalence of cervical HPV infection per age group}

As expected, the highest HPV prevalence found in our study was observed in women aged 18-24 years (26.7\%), an age group potentially associated with a higher number of sexual partners. This finding was also observed in previous Spanish and European studies. ${ }^{916}{ }^{17}$ In our study, after this first peak in women $<25$ years, the prevalence declines in older ages, although a slightly, not significant, increased was observed in women older than 55 years. This second peak in older women was also reported by other authors. ${ }^{17} 18$ 20-22 Such a bimodal pattern could be due to changes in the sexual behaviour or the reactivation of latent viral infections, ${ }^{25} \mathrm{HPV}$ types and their variants in such infections, individual susceptibility or regional differences in the screening programmes. ${ }^{18}$

\section{HPV genotypes}

HPV 16 was the most prevalent genotype in our population, present in $27.8 \%$ of positive samples. This prevalence was similar to that reported in other studies in Spain, ${ }^{10}{ }^{14}$ although higher than the $16.9 \%$ found in the CLEOPATRE study. ${ }^{9}$ After HPV 16, the most frequent types in decreasing order were: HPV 51, 53, 59, 31 and 52. Our results are similar to most studies conducted in Spain ${ }^{9-1114}$ and other European countries. ${ }^{19}$ 21-24 
Table 3 Human papillomavirus (HPV) type-specific distribution of the most common types ( $n=6010$ women)

\begin{tabular}{|c|c|c|c|}
\hline HPV type & $\begin{array}{l}\text { Number of HPVpositive } \\
\text { women }(n=820)\end{array}$ & $\begin{array}{l}\text { HPV prevalenceamong all } \\
\text { women }(n=6010)(\% ; 95 \% \mathrm{Cl})\end{array}$ & $\begin{array}{l}\text { HPV prevalence amongpositive } \\
\text { women }(\mathrm{n}=820)(\% ; 95 \% \mathrm{Cl})\end{array}$ \\
\hline Single types & 359 & $6.0(5.4$ to 6.6$)$ & 43.8 (40.4 to 47.2 ) \\
\hline \multicolumn{4}{|l|}{ HR HPV types* } \\
\hline 16 & 75 & $1.2(1.0$ to 1.5$)$ & 9.1 (7.2 to 11.1$)$ \\
\hline 51 & 34 & 0.6 (0.4 to 0.8$)$ & 4.1 (2.8 to 5.5 ) \\
\hline 53 & 28 & 0.5 (0.3 to 0.6$)$ & 3.4 (2.2 to 4.7$)$ \\
\hline 31 & 16 & 0.3 (0.1 to 0.4$)$ & 2.0 (1.0 to 2.9 ) \\
\hline 59 & 14 & 0.2 (0.1 to 0.4$)$ & 1.7 (0.8 to 2.6$)$ \\
\hline $33,68,70$ & 11 each & $0.2(0.1$ to 0.3$) \dagger$ & $1.3(0.6$ to 2.1$) \dagger$ \\
\hline 66 & 10 & 0.2 (0.1 to 0.3$)$ & 1.2 (0.5 to 2.0$)$ \\
\hline 52 to 58 & Nine each & 0.1 (0.1 to 0.2$) \dagger$ & $1.1(0.4$ to 1.8$) \dagger$ \\
\hline 18 & 8 & 0.1 (0.0 to 0.2 ) & $1.0(0.3$ to 1.6$)$ \\
\hline 56 & 7 & 0.1 (0.0 to 0.2$)$ & 0.9 (0.2 to 1.5$)$ \\
\hline 35 to 39 & Five each & 0.1 (0.0 to 0.2$) \dagger$ & $0.6(0.1$ to 1.1$) \dagger$ \\
\hline 73 & 4 & 0.1 (0.0 to 0.1$)$ & 0.5 (0.0 to 1.0$)$ \\
\hline 45 & 3 & $0.0(0.0$ to 0.1$)$ & 0.4 (0.0 to 0.8$)$ \\
\hline 67 & 2 & $0.0(0.0$ to 0.1$)$ & 0.2 (0.1 to 0.6$)$ \\
\hline $69,69 / 71$ & One each & $0.0(0.0$ to 0.0$) \dagger$ & $0.1(0.1$ to 0.4$) \dagger$ \\
\hline \multicolumn{4}{|l|}{ LR HPV types $\ddagger$} \\
\hline 42 & 17 & 0.3 (0.1 to 0.4$)$ & 2.1 (1.1 to 3.0 ) \\
\hline 84 & 12 & $0.2(0.1$ to 0.3$)$ & 1.5 (0.6 to 2.3 ) \\
\hline 62 & 11 & 0.2 (0.1 to 0.3$)$ & 1.3 (0.6 to 2.1$)$ \\
\hline 61 & 10 & 0.2 (0.1 to 0.3$)$ & 1.2 (0.5 to 2.0$)$ \\
\hline $6,55,81$ & 9 & 0.1 (0.1 to 0.2 ) & 1.1 (0.4 to 1.8$)$ \\
\hline 89 & 5 & 0.1 (0.0 to 0.2 ) & 0.6 (0.1 to 1.1$)$ \\
\hline 54 & 4 & 0.1 (0.0 to 0.1$)$ & 0.5 (0.0 to 1.0$)$ \\
\hline $11,43,72,83$ & Two each & $0.0(0.0$ to 0.1$) \dagger$ & $0.2(0.1$ to 0.6$) \dagger$ \\
\hline 40 & 1 & $0.0(0.0$ to 0.0$)$ & 0.1 (0.1 to 0.4$)$ \\
\hline Untyped HPV & 28 & $0.5(0.3$ to 0.6$)$ & 3.4 (2.2 to 4.7$)$ \\
\hline Multiple types & 433 & $7.2(6.6$ to 7.9$)$ & 52.8 (49.4 to 56.2$)$ \\
\hline \multicolumn{4}{|c|}{ Number of multiple types } \\
\hline Two types & 203 & 3.4 (2.9 to 3.8$)$ & 24.8 (21.8 to 27.7 ) \\
\hline Three types & 115 & 1.9 (1.6 to 2.3$)$ & $14.0(11.6$ to 16.4$)$ \\
\hline Four types & 73 & $1.2(0.9$ to 1.5$)$ & $8.9(7.0$ to 10.9$)$ \\
\hline Five or more types & 42 & 0.7 (0.5 to 0.9$)$ & 5.1 (3.6 to 6.6$)$ \\
\hline \multicolumn{4}{|c|}{ Most frequent combinations } \\
\hline 16 with others & 153 & 2.5 (2.1 to 2.9$)$ & 18.7 (16 to 21.3$)$ \\
\hline 53 with others & 81 & $1.3(1.1$ to 1.6$)$ & 9.9 (7.8 to 11.9$)$ \\
\hline 51 with others & 78 & $1.3(1.0$ to 1.6$)$ & 9.5 (7.5 to 11.5$)$ \\
\hline 59 with others & 67 & $1.1(0.8$ to 1.4$)$ & $8.2(6.3$ to 10.0$)$ \\
\hline 42 with others & 59 & $1.0(0.7$ to 1.2$)$ & 7.2 (5.4 to 9.0$)$ \\
\hline 31 with others & 54 & $0.9(0.7$ to 1.1$)$ & 6.6 (4.9 to 8.3$)$ \\
\hline 52 with others & 54 & $0.9(0.7$ to 1.1$)$ & 6.6 (4.9 to 8.3$)$ \\
\hline 66 with others & 50 & 0.8 (0.6 to 1.1$)$ & 6.1 (4.5 to 7.7$)$ \\
\hline 54 with others & 48 & 0.8 (0.6 to 1.0$)$ & $5.9(4.2$ to 7.5$)$ \\
\hline
\end{tabular}


Table 3 Continued

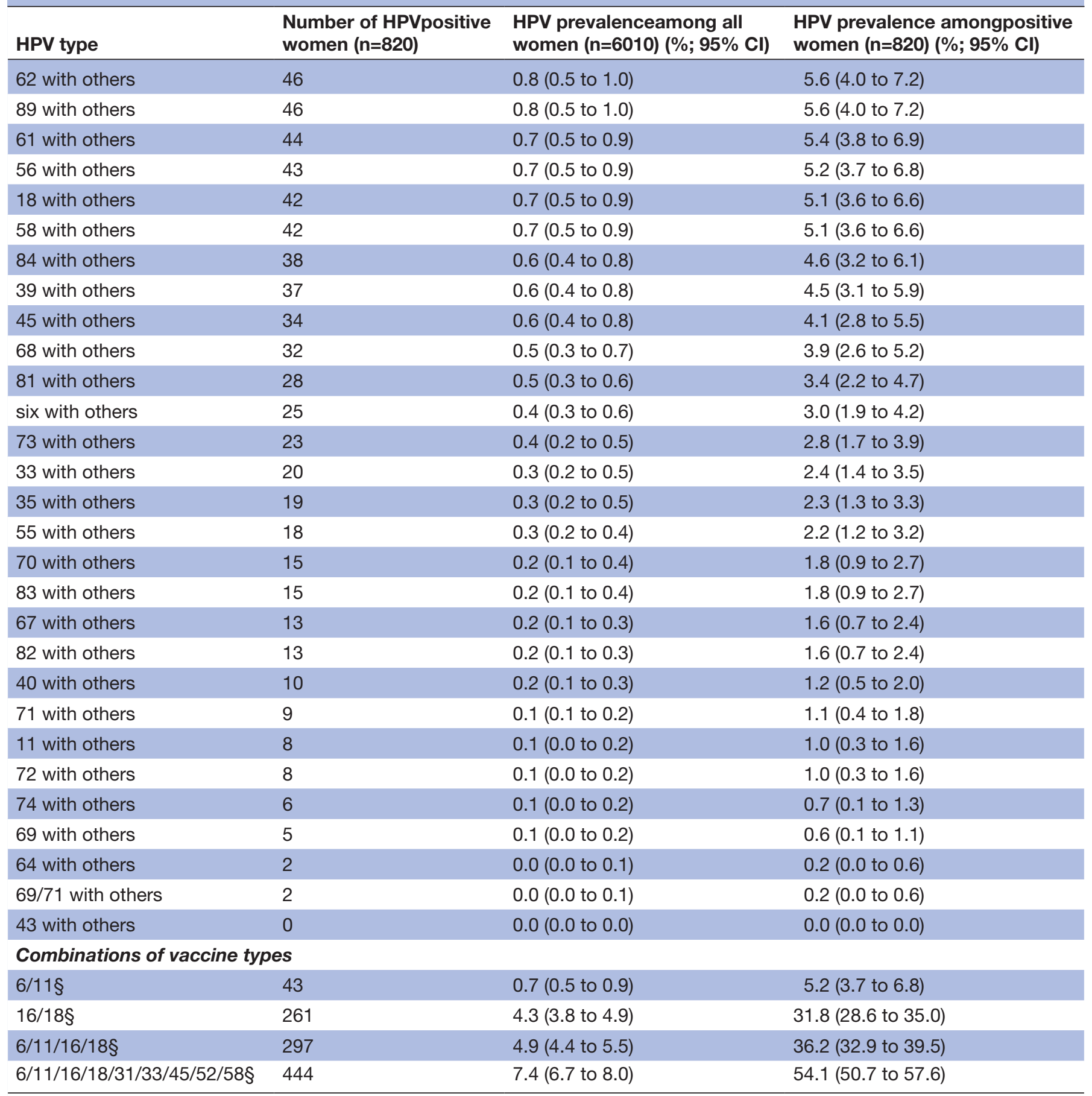

Bold is used to highlight the three main groups of determinations: single, multiple and untyped.

${ }^{*} \mathrm{HR}$ types include high-risk types and possibly/probably high-risk types: $16,18,31,33,35,39,45,51,52,56,58,59,53,66,67,68,69$, 69/71, 70, 73.

†HPV prevalence for each of the types in the row.

łLR types include 6, 11, 40, 42, 43, 54, 55, 61, 62, 72, 81, 83, 84, 89.

$\S$ One or more of the vaccine types are concerned.

HPV, human papillomavirus; HR, high-risk; LR, low risk.

Many studies have reported the percentage of multiple infections $912131518-212324$ ranging from 8.1\% in Spain ${ }^{13}$ to $54.3 \%$ in Denmark. ${ }^{24}$ The one from Denmark was similar to ours $(52.8 \%)$, although it included a higher percentage of infections by more HPV types. This finding could be explained by the use of a HPV detection technique (hybridisation technology) with a high sensitivity for detecting multiple infections.

A total of $31.8 \%$ of HPV-positive women $(4.3 \%$ of the total population) were infected by types 16 and/or 18 , 
Table 4 Crude and multivariate analyses of the association between cervical human papillomavirus (HPV) infection and selected subjects' characteristics ( $\mathrm{n}=6010$ women)

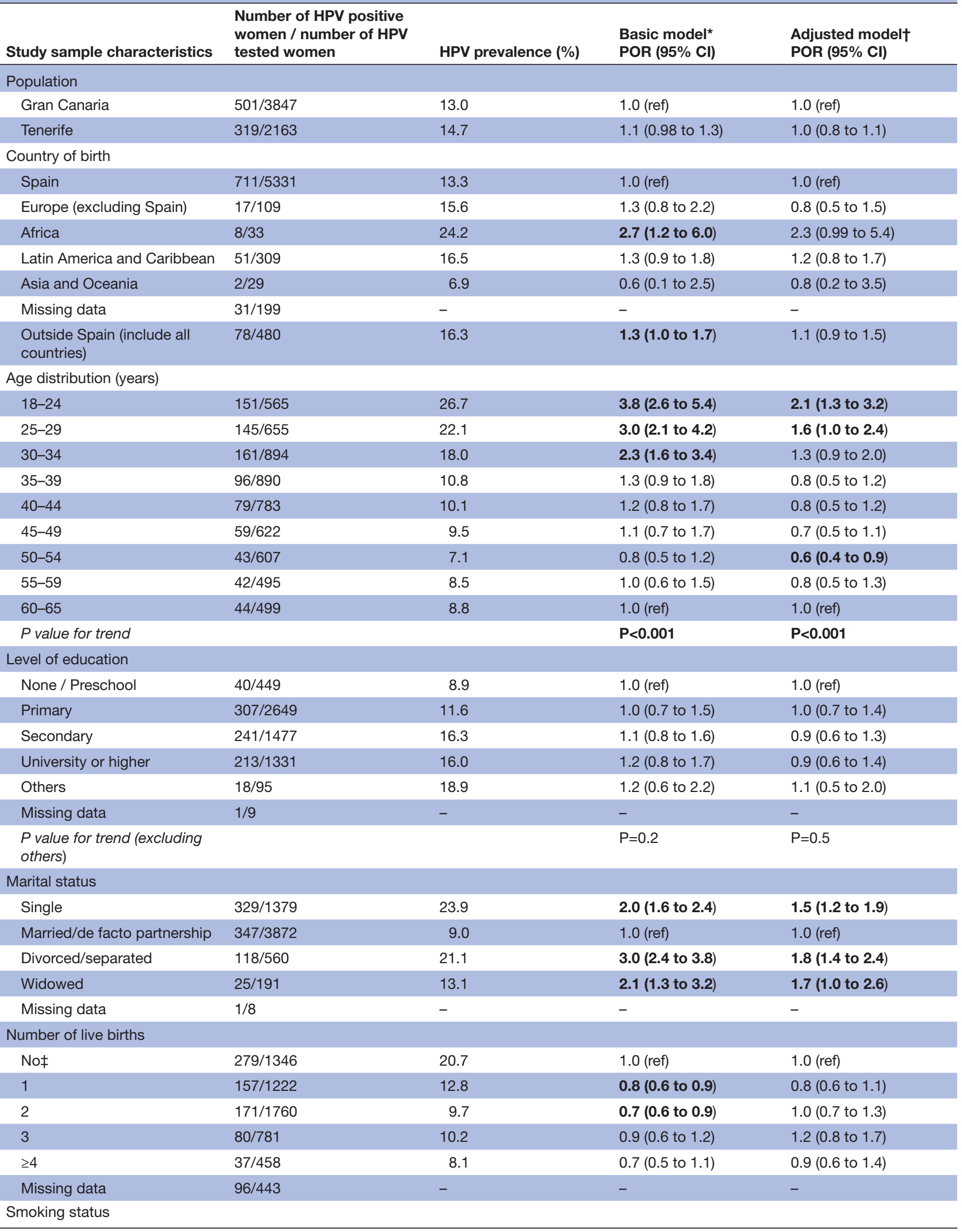


Table 4 Continued

\begin{tabular}{|c|c|c|c|c|}
\hline Study sample characteristics & $\begin{array}{l}\text { Number of HPV positive } \\
\text { women / number of HPV } \\
\text { tested women }\end{array}$ & HPV prevalence (\%) & $\begin{array}{l}\text { Basic model* } \\
\text { POR }(95 \% \mathrm{CI})\end{array}$ & $\begin{array}{l}\text { Adjusted model } † \\
\text { POR }(95 \% \mathrm{Cl})\end{array}$ \\
\hline Never smoked & $376 / 3402$ & 11.1 & 1.0 (ref) & 1.0 (ref) \\
\hline Ex smoker & $126 / 900$ & 14.0 & $1.4(1.1$ to 1.7$)$ & $1.2(0.9$ to 1.5$)$ \\
\hline Current smoker & $318 / 1708$ & 18.6 & $1.7(1.5$ to 2.1$)$ & $1.2(1.0$ to 1.5$)$ \\
\hline \multicolumn{5}{|c|}{ Age at first sexual intercourse (years) } \\
\hline $15-16$ & $166 / 817$ & 20.3 & 1.4 (0.99 to 2.1$)$ & 0.8 (0.5 to 1.2$)$ \\
\hline $17-18$ & $273 / 1835$ & 14.9 & $1.1(0.8$ to 1.6$)$ & 0.7 (0.5 to 1.1$)$ \\
\hline $19-20$ & $143 / 1266$ & 11.3 & $0.9(0.7$ to 1.3$)$ & 0.7 (0.5 to 1.1$)$ \\
\hline $21-25$ & $146 / 1402$ & 10.4 & $1.0(0.7$ to 1.4$)$ & 0.9 (0.6 to 1.3$)$ \\
\hline$>25$ & $45 / 437$ & 10.3 & 1.0 (ref) & 1.0 (ref) \\
\hline 1 & $214 / 3189$ & 6.7 & 1.0 (ref) & 1.0 (ref) \\
\hline $2-3$ & $274 / 1545$ & 17.7 & 2.7 (2.2 to 3.3$)$ & 2.3 (1.9 to 2.8 ) \\
\hline $4-5$ & $141 / 613$ & 23.0 & $3.6(2.8$ to 4.6$)$ & 2.8 (2.2 to 3.6$)$ \\
\hline $6-10$ & $119 / 395$ & 30.1 & 5.3 (4.0 to 6.9$)$ & 3.9 (2.9 to 5.2$)$ \\
\hline $11-20$ & $41 / 126$ & 32.5 & 5.9 (3.9 to 8.8$)$ & 4.2 (2.8 to 6.5$)$ \\
\hline$>20$ & $18 / 49$ & 36.7 & 8.1 (4.4 to 14.8$)$ & 6.2 (3.3 to 11.5$)$ \\
\hline Missing data & $13 / 93$ & - & - & - \\
\hline$P$ value for trend & & & $P<0.001$ & $P<0.001$ \\
\hline \multicolumn{5}{|l|}{ Use of oral contraceptives } \\
\hline No & $645 / 4986$ & 12.9 & 1.0 (ref) & 1.0 (ref) \\
\hline Yes & $84 / 378$ & 22.2 & 2.1 (1.6 to 2.7$)$ & $1.6(1.2$ to 2.1$)$ \\
\hline Missing data§ & $91 / 646$ & - & - & - \\
\hline \multicolumn{5}{|l|}{ Genital warts } \\
\hline Never & $783 / 5894$ & 13.3 & 1.0 (ref) & 1.0 (ref) \\
\hline Ever & $37 / 116$ & 31.9 & 2.8 (1.8 to 4.2$)$ & 1.7 (1.1 to 2.6$)$ \\
\hline
\end{tabular}

Bold is used to highlight the three main groups of determinations: single, multiple and untyped.

*Basic model: adjusted for age group (18-24, 25-34, 35-44, 45-54, 55-65 years) and population (Gran Canaria, Tenerife).

†Adjusted model: adjusted for age group, population, level of education, marital status, smoking habits, lifetime number of sexual partners, previous cervical lesions, ever use of rhythm method and ever had genital warts.

flncludes women who were pregnant but had 0 live births.

§lncludes 'Do not know' in the 'Missing data' category.

POR, prevalence odds ratio.

which were included in the bivalent vaccine. Regarding HPV types included in the quadrivalent vaccine (HPV 6, 11,16 and 18), at least one of them was found in $36.2 \%$ of women (4.9\% of the total population). This prevalence increased up to $54.1 \%$ with the addition of HPV types $31 / 33 / 45 / 52 / 58$, included in the nonavalent vaccine. Such proportions were higher than those reported in
Denmark $^{24}(27.7 \%)$ and in the CLEOPATRE study $(22.1 \%$ in Spain ${ }^{9}$ and $32.6 \%$ in Portugal ${ }^{23}$ ). These data illustrate the degree of protection offered by HPV vaccines; one out of three HPV-infected women would have been protected by the bivalent or the quadrivalent vaccine and one out of two women would have been protected by the nonavalent one. However, the frequency of HPV types 51, 53, 59, 
frequently found in our population, indicate the need to continue the cytological screening population.

\section{Cytopathological study and cervical HPV infection}

Cytological alterations found in our study $(5.3 \%)$ were similar to those observed in other studies, both in Spain $^{91014}$ and Europe, ${ }^{19} 2022-24$ ranging between 1.6\% and $7 \%$. The HPV prevalence increased with lesion severity $(60.7 \%$ in women with ASCUS; $86.8 \%$ in women with LSIL and $83.3 \%$ in women with HSIL+). This finding was in agreement with other published studies. ${ }^{9} 10121921-24$ The HPV prevalence in normal cytologies was $10.6 \%$, similar to that reported by Bruni et $a l^{18}$ in our geographical area $(8.8 \%)$, although lower than that reported in most studies. ${ }^{9}{ }^{21-24}$

\section{Risk factors and cervical HPV infection}

Age consistently appears as a risk factor for HPV infection, both in our study and other published ones, ${ }^{14} 202627$ directly associated with younger women's sexual behaviour as compared with older ones.

Number of sexual partners in life extensively appears $^{10} 1114$ 26-28 as a risk factor for HPV infection and was the factor with the largest impact in our study. As in our study, most authors failed to find a relationship with age at first intercourse. ${ }^{102627}$ This later parameter seems to influence number of sexual partners but does not seem to be an independent risk factor for HPV infection.

In our analysis, not being married (divorced, widow or single) was a statistically significant risk factor for HPV infection, as was also reported in other studies. ${ }^{102026}$ This finding could be explained by the sexual behaviour of not married women, who may probably have more sexual partners.

Coitus interruptus was the only contraception-related practice found to be associated with higher risk of anytype HPV infection, both in the basic and the adjusted models, although such an association was not found for HR-HPV types. This factor might possibly be linked to younger groups, where other risk increasing factors coexist.

Smoking was a risk factor for HPV infection in our population, in accordance with data reported by other authors, ${ }^{2627} 29$ although not by others. ${ }^{10}$ Quitting smoking has been considered to potentially revert infection risk. ${ }^{29}$ In order to explain for the relationship between smoking and increased risk of HPV infection, it has been postulated that tobacco and its metabolites may alter the immune system of the cervical epithelium, thus reducing the number of CD4 lymphocytes and Langerhans cells ${ }^{29}$ and impairing the activity of natural killer cells.

The presence of genital warts and previous cervical alterations was associated with higher risk in our population, as well as in other studies, ${ }^{26}$ which is not surprising since both events are directly related.

Country of origin especially African ones, appeared as a risk factor for HPV infection in our basic model, although not in our adjusted model. Earlier published Spanish studies showed higher HPV infection risk in women born out of Spain, ${ }^{10}{ }^{11} 26$ probably due to differences in the sexual behaviour of men and women.

Regarding parity and HPV infection risk, similar to other authors, ${ }^{20}$ we found some protective effect in women with one or two births in our basic model for any-type HPV, although not for the adjusted model or for HR-HPV types, a finding also reported by some authors. ${ }^{10} 2627$ In a metaanalysis published by the IARC, ${ }^{30}$ a slight risk increase in nulliparous women (younger and more sexually active) as compared with women who have been pregnant was described.

The relationship between taking oral contraceptives (OC) and the risk of HPV infection is controversial. In our population, a slightly increased risk was found for women taking OC in the basic model though not in the adjusted model, a finding also described in other studies. ${ }^{1020262730}$

Infection by other sexually transmitted diseases analysed in our population increased the risk in the basic model but not in the adjusted model (data not shown), consistent with other published studies. ${ }^{2627}$

Some authors have reported no association between using condoms and increased risk of HPV infection $^{14} 202728$; some even reported some protective effect. ${ }^{26}$ In our study, like with other contraceptive methods we failed to find an association with HPV infection (data not shown). The evidence is controversial regarding the association between HPV infection and level of education. ${ }^{262731}$

\section{Strengths and weaknesses}

One of the main strengths of our study was our populationbased design, which covered the main healthcare centres on the islands and recruited potential participants from an official source, ensuring a random sample. Additionally, the fact that all cytological and molecular studies were conducted in the same laboratory, by the same technical and medical staff, using highly sensitive and partially automated analytic systems ensured consistency, homogeneity and reproducibility of diagnostic methods.

The prolonged recruitment time was a weakness of this study. Three years were needed for Tenerife and 6 years for Gran Canaria, although 2 years had been originally planned. Potential variations over time could have influenced the sociodemographic characteristics of the population. Thus, the characteristics of participants recruited at the beginning of the recruitment period could have been different from those of women recruited by the end.

\section{CONCLUSIONS}

This study provides population-based references for the prevalence of HPV infection in the Canary Islands, which enables future assessment of the impact of HPV vaccination campaigns. The prevalence of $\mathrm{HPV}$ infection in the female population of Gran Canaria and Tenerife was high, although similar to that of previous studies conducted in Spain, with genotype HPV 16 being the 
most frequent one. These results support the potential benefits of HPV vaccines in terms of reducing infection as well as the consequent development of HPV-related lesions, including cancer.

\section{Author affiliations}

${ }^{1}$ Department of Pathology, Complejo Hospitalario Universitario Insular Materno Infantil, Las Palmas de Gran Canaria, Spain

${ }^{2}$ Unit of Infections and Cancer-Information and Interventions (UNIC-I\&I)-Cancer Epidemiology Research Program (CERP)-Institut d'Investigació Biomèdica de Bellvitge (IDIBELL), Catalan Institute of Oncology, L'Hospitalet de Llobregat, Spain ${ }^{3}$ Centro de Investigación Biomédica en Red de Epidemiología y Salud Pública (CIBERESP), Madrid, Spain

${ }^{4}$ Department of Obstetrics and Gynecology, Complejo Hospitalario Universitario Insular Materno Infantil, Las Palmas de Gran Canaria, Spain

${ }^{5}$ Department of Obstetrics and Gynecology, Hospital Universitario de Canarias, La Laguna, Spain

${ }^{6}$ Department of Obstetrics and Gynecology, Hospital Universitario Nuestra Señora de la Candelaria, Santa Cruz de Tenerife, Spain

${ }^{7}$ Department of Pathology, Hospital Universitario de Canarias, La Laguna, Spain

${ }^{8}$ Reproductive Health Global Programme, PATH, Seattle, Washington, USA

${ }^{9}$ Cancer Epidemiology Research Program (CERP)-Institut d'Investigació Biomèdica

de Bellvitge (IDIBELL), Catalan Institute of Oncology, L'Hospitalet de Llobregat, Spain

${ }^{10}$ Centro de Investigación Biomédica en Red de Cáncer (CIBERONC), Madrid, Spain

\section{Twitter Miguel Andujar @AAB-7690-2020}

Acknowledgements The authors would like to thank all patients for their participation in the study. The authors would like to thank the colleagues and the study staff for their commitment to data collection and to Dr Jorge Luis Doreste from University of Las Palmas de Gran Canaria for statistical analysis for simple size of the study. The authors would like to thank Tenesoya Alamo, Tanausú de la Cruz and Maria Dolores Navarro for technical assistance. The authors would also like to thank Sanofi Pasteur MSD (Merck Sharp \& Dome), Roche Diagnostics SL and Fujirebio Ibérica SL for receiving donations for analytical kits.

Collaborators HPV Canary Study Group. Gran Canaria Team: Diana Alemán, Mónica Almeida, Ana María Arencibia, María Isabel Armas, Guillermina Batista, Victoria Bernal, Francisca Bernaldo de Quirós, Sili Bolaños, Dolores Casaña, Luisa Celedón, Isabel Cruz, Elisa Díaz, Inocencia Duarte, Felisa Expósito, Carmelo Felipe, Carlos Galván, María José García, María Isabel García, Vanesa García, Virginia García, Elena Giménez, Teresa Godoy, Catalina Gómez, Lucia González, Luisa Gutiérrez, Mónica Hernández, Delia Herrera, Laura Herrera, Rosario Laseca, Carmen Marrero, Ofelia Marrero, Noa Mateos, Olivia Medina, Josefa Mendoza, Lucia Montesdeoca, Rosa Monzón, Cristina Morales, Mercedes Morales, M Dolores Navarro, María Ángeles Nieto, Noelia Pérez, Yurena Pérez, Antonio Ramos, Antonio Rico, Margarita Roldán, Esther Salamanca, Rosario Sánchez, Raquel Santana, Elvira Santos, Antonia Solanes, Elisabeth Soutto, Dulce Suarez, María Jesús Suárez, María Ángeles Tadeo, Virgen Valdés, Gabriela Valido, Iralla Vega, Maria del Pino Vega. Tenerife Team: María Angeles Afonso, Elisa Baena, María Pilar Baz, José de Armas, Alicia de la Puerta, Josefina García, María Asuncion González, Célida González, María Teresa Hernández, Josefa Limiñana, Carmen Rosa León, Fernando Marín, Emma Manrique, José Roberto Negrín, Rosa Olavarrieta, Verónica Perera, Concepción Sabater, Candelaria Sosvilla.

Contributors MA designed the study, performed HPV diagnostic molecular methods, data analysis, interpretation of data and drafted the manuscript. ER performed statistical analysis of data, designed the figures and drafted the manuscript. MP performed cytopathological diagnosis. MS performed HPV diagnostic molecular methods. MAS designed and supervised a base data and processed the experimental data. AT, BV, LA, RH, HPV Canary Study Group received the patients and took cervical samples. MdCC and ARdP were involved in planning and supervised the management of cervical a molecular samples. AL, JLT, OA, VB, $\mathrm{NM}, \mathrm{SC}, \mathrm{AQ}$ treated patients with cytological and molecular disorders. LB, SdS and ES aided in interpreting the results and worked on the manuscript. All authors read and approved the final manuscript.

Funding This research has been funded by: Fondo de Investigación Sanitaria (Instituto de Salud Carlos III), grant FIS 00/714; Fundación Canaria de Investigación y Salud, grant FUNCIS 00/14 and FUNCIS 02/19 and Fundación Amurga.
Disclaimer The funders had neither any involvement in the study design, collection, analysis, interpretation of the data, writing of the report nor in the decision to submit the paper for publication.

Competing interests None declared.

Patient consent for publication Not required.

Ethics approval This study was favourably evaluated by the Ethics and Clinical Trial Committee of the hospital Complejo Hospitalario Universitario Insular Materno Infantil.

Provenance and peer review Not commissioned; externally peer reviewed.

Data availability statement Data are available on reasonable request. The database obtained from this study is kept under the supervision of the authors (MA and ER) in an anonymised form. These data will be shared in a raw form by emailing to mandsan@gobiernodecanarias.org.

Open access This is an open access article distributed in accordance with the Creative Commons Attribution Non Commercial (CC BY-NC 4.0) license, which permits others to distribute, remix, adapt, build upon this work non-commercially, and license their derivative works on different terms, provided the original work is properly cited, appropriate credit is given, any changes made indicated, and the use is non-commercial. See: http://creativecommons.org/licenses/by-nc/4.0/.

ORCID iD

Miguel Andujar http://orcid.org/0000-0002-4858-6915

\section{REFERENCES}

1 Ferlay J, Ervik M, Lam F, et al. Global cancer observatory: cancer today. Lyon, France: international agency for research on cancer, 2018. Available: https://gco.iarc.fr/today

2 Health Service Government of Canary Islands. Available: http:// www3.gobiernodecanarias.org/sanidad/scs [Accessed 2 Sep 2019].

3 Bray F, Colombet M, Mery L. Cancer incidence in five continents, Vol. XI (electronic version). Lyon: International Agency for Research on Cancer, 2017. http://ci5.iarc.fr

4 Bosch FX, Lorincz A, Muñoz N, et al. The causal relation between human papillomavirus and cervical cancer. J Clin Pathol 2002;55:244-65.

5 Muñoz N, Bosch FX, de Sanjosé S, et al. Epidemiologic classification of human papillomavirus types associated with cervical cancer. $N$ Engl J Med 2003;348:518-27.

6 de Sanjosé S, Quint WG, Alemany L, et al. Human papillomavirus genotype attribution in invasive cervical cancer: a retrospective cross-sectional worldwide study. Lancet Oncol 2010;11:1048-56.

7 Schiller JT, Castellsagué X, Garland SM. A review of clinical trials of human papillomavirus prophylactic vaccines. Vaccine 2012;30:F123-38.

8 Joura EA, Giuliano AR, Iversen O-E, et al. A 9-valent HPV vaccine against infection and intraepithelial neoplasia in women. $N$ Engl J Med Overseas Ed 2015;372:711-23.

9 Castellsagué X, Iftner T, Roura E, et al. Prevalence and genotype distribution of human papillomavirus infection of the cervix in Spain: the CLEOPATRE study. J Med Virol 2012;84:947-56.

10 de Sanjosé S, Almirall R, Lloveras B, et al. Cervical human papillomavirus infection in the female population in Barcelona, Spain. Sex Transm Dis 2003;30:788-93.

11 González C, Ortiz M, Canals J, et al. Higher prevalence of human papillomavirus infection in migrant women from Latin America in Spain. Sex Transm Infect 2006;82:260-2.

12 Bernal M, Burillo I, Mayordomo JI, et al. Human papillomavirus (HPV) infection and intraepithelial neoplasia and invasive cancer of the uterine cervix: a case-control study in Zaragoza, Spain. Infect Agent Cancer 2008;3:8.

13 Martorell M, García-García JA, Ortiz C, et al. Prevalence and distribution of human papillomavirus findings in swab specimens from gynaecology clinics of the East coast of Spain. Scand J Infect Dis 2010;42:549-53.

14 Trigo-Daporta M, García-Campello M, Pérez-Ríos M, et al. High-risk human papillomavirus in galicia, Spain: prevalence and evaluation of the sample representativeness. Scand J Infect Dis 2014;46:737-44.

15 García S, Dominguez-Gil M, Gayete J, et al. [Prevalence of human papillomavirus in Spanish women from a population screening program]. Rev Esp Quimioter 2017;30:177-82.

16 de Sanjosé S, Cortés X, Méndez C, et al. Age at sexual initiation and number of sexual partners in the female Spanish population 
results from the AFRODITA survey. Eur J Obstet Gynecol Reprod Biol 2008; 140:234-40.

17 De Vuyst H, Clifford G, Li N, et al. HPV infection in Europe. Eur J Cancer 2009;45:2632-9.

18 Bruni L, Diaz M, Castellsagué X, et al. Cervical human papillomavirus prevalence in 5 continents: meta-analysis of 1 million women with normal cytological findings. J Infect Dis 2010;202:1789-99.

19 Klug SJ, Hukelmann M, Hollwitz B, et al. Prevalence of human papillomavirus types in women screened by cytology in Germany. $J$ Med Virol 2007;79:616-25.

20 Ronco G, Ghisetti V, Segnan N, et al. Prevalence of human papillomavirus infection in women in Turin, Italy. Eur $\mathrm{J}$ Cancer 2005;41:297-305.

21 Heard I, Tondeur L, Arowas L, et al. Human papillomavirus types distribution in organised cervical cancer screening in France. PLoS One 2013;8:e79372.

22 Arbyn M, Benoy I, Simoens C, et al. Prevaccination distribution of human papillomavirus types in women attending at cervical cancer screening in Belgium. Cancer Epidemiol Biomarkers Prev 2009;18:321-30.

23 Pista A, de Oliveira CF, Cunha MJ, et al. Prevalence of human papillomavirus infection in women in Portugal: the CLEOPATRE Portugal study. Int J Gynecol Cancer 2011;21:1150-8.

24 Kjaer SK, Breugelmans G, Munk C, et al. Population-Based prevalence, type- and age-specific distribution of HPV in women before introduction of an HPV-vaccination program in Denmark. Int $J$ Cancer 2008;123:1864-70.
25 Gravitt PE, Rositch AF, Silver MI, et al. A cohort effect of the sexual revolution may be masking an increase in human papillomavirus detection at menopause in the United States. $J$ Infect Dis 2013;207:272-80.

26 Roura E, Iftner T, Vidart JA, et al. Predictors of human papillomavirus infection in women undergoing routine cervical cancer screening in Spain: the CLEOPATRE study. BMC Infect Dis 2012;12:145.

27 Pista A, de Oliveira CF, Cunha MJ, et al. Risk factors for human papillomavirus infection among women in Portugal: the CLEOPATRE Portugal study. Int J Gynaecol Obstet 2012;118:112-6.

28 Vaccarella S, Franceschi S, Herrero R, et al. Sexual behavior, condom use, and human papillomavirus: pooled analysis of the IARC human papillomavirus prevalence surveys. Cancer Epidemiol Biomarkers Prev 2006;15:326-33.

29 Vaccarella S, Herrero R, Snijders PJF, et al. Smoking and human papillomavirus infection: pooled analysis of the International agency for research on cancer HPV prevalence surveys. Int J Epidemiol 2008;37:536-46.

30 Vaccarella S, Herrero R, Dai M, et al. Reproductive factors, oral contraceptive use, and human papillomavirus infection: pooled analysis of the IARC HPV prevalence surveys. Cancer Epidemiol Biomarkers Prev 2006;15:2148-53.

31 Franceschi S, Plummer M, Clifford G, et al. Differences in the risk of cervical cancer and human papillomavirus infection by education level. Br J Cancer 2009;101:865-70. 